\title{
Time needed to perform intermittent catheterization in adults with spinal cord injury: A pilot randomized controlled cross-over study
}

\section{Authors:}

Karthik Gopalakrishnan ${ }^{1,2}$, Nick Fabrin Nielsen ${ }^{3}$, Andrea L. Ramirez ${ }^{1}$, Jeppe Sørensen ${ }^{3}$, Matthias Walter ${ }^{1,4, \#}$, Andrei V. Krassioukov ${ }^{1,5,6, \#}$

\# These authors share the senior authorship.

\section{Affiliations:}

1 International Collaboration on Repair Discoveries, Faculty of Medicine, The University of British Columbia, Vancouver, British Columbia, Canada.

2 MD Undergraduate Program, Faculty of Medicine, The University of British Columbia, Vancouver, British Columbia, Canada

3 Global Market Access, Coloplast A/S, Humlebæk, Denmark

4 Department of Urology, University Hospital Basel, University of Basel, Basel, Switzerland 5 Division of Physical Medicine and Rehabilitation, Faculty of Medicine, The University of British Columbia, Vancouver, British Columbia, Canada.

6 G.F. Strong Rehabilitation Centre, Vancouver, British Columbia, Canada.

\section{Corresponding author:}

Andrei V. Krassioukov MD, PhD, FRCPC

International Collaboration on Repair Discoveries

Blusson Spinal Cord Centre

818 West 10th Avenue,

Vancouver, British Columbia V5Z 1M9, Canada.

Email: krassioukov@icord.org

Key words:

Hydrophilic catheter, non-hydrophilic catheter, intermittent catheterization, time, preparation, satisfaction, spinal cord injury 


\section{ABSTRACT}

\section{Background:}

Intermittent catheterization (IC), considered the gold standard for bladder management for individuals with spinal cord injury (SCl) with sufficient dexterity, is usually performed using hydrophilic (HPC) or non-hydrophilic (non-HPC) catheters. Currently, there is no evidence on the temporal burden associated with IC with either catheter.

\section{Objective:}

To compare both catheters regarding their time requirement for IC and participant satisfaction.

\section{Design, setting and participants:}

Twenty individuals with chronic (>1-year) SCl at any spinal segment were randomized to undergo two cross-over assessments within 10 days (i.e., either starting with HPC or nonHPC). We measured time taken to perform IC using a 13 step pre-determined IC protocol (e.g., enter bathroom, wash hands, transfer to toilet, etc.). Furthermore, we assessed user satisfaction of both catheters using a Likert scale (i.e., strongly agree $=5$, strongly disagree $=1$ ).

\section{Outcome measures and statistical analysis:}

Time (i.e., for each step and in total) to perform IC and participant satisfaction were compared between catheters using non-parametric statistics, i.e., Wilcoxon rank sign tests. Results are presented as median with interquartile range.

\section{Results and limitations:}

Participants using HPCs spent less time to prepare a catheter [15 s (10-20) vs. 41 (20-69), $\mathrm{p}=0.002$ ] and overall to perform IC [283 s (242-352) vs. 373 (249-441), $p=0.01$ ] compared to non-HPCs. Moreover, participants rated the preparation of HPCs to be easier [5 (4-5) vs. 4 (2-4), $p=0.047$ ] compared to non-HPCs. The key limitation of this pilot study was the sample size.

\section{Conclusions:}

Preparation and usage of HPCs for IC is easier and faster compared to non-HPCs. IC can be a significant temporal burden for $\mathrm{SCl}$ individuals.

\section{Patient summary:}

We compared coated and uncoated catheters on time needed for intermittent catheterization and user satisfaction in individuals with spinal cord injury. Participants can manually empty their bladder quicker and easier with coated compared to uncoated catheters. 


\section{INTRODUCTION}

Spinal cord injury (SCI) poses a significant burden on affected individuals and their quality of life (QoL). ${ }^{1}$ Adult neurogenic lower urinary tract dysfunction (ANLUTD) is a common complication resulting from damage to the sensorimotor and autonomic nervous system ${ }^{2}$, entailing urinary storage and/or voiding dysfunctions potentially jeopardizing the entire urinary tract if left untreated. ${ }^{3}$

Intermittent catheterization (IC) is considered the gold standard for bladder management for individuals with $\mathrm{SCl}$ with sufficient dexterity ${ }^{4}$. There are two main types of catheters for IC. Hydrophilic catheters (HPC) have a polymer coating which binds to water ${ }^{5}$ leading to a smooth and slippery surface. HPCs do not require manual lubrication and are usually pre-packaged in sterile water. ${ }^{6}$ In contrast, uncoated non-hydrophilic catheters (nonHPC) require manual lubrication to reduce insertion-related friction. ${ }^{7}$ Over the last decade, HPCs have been associated with decreased incidence of urinary tract infections (UTIs) compared to non-HPCs ${ }^{8}$, but considering the heterogeneity with respect to the definition of UTIs in these studies ${ }^{9}$, definitive comparisons between catheter types regarding the incidence of related UTIs are still pending. ${ }^{10}$

The slippery surface of HPCs appears to reduce friction as well as the incidence of urethral injuries. ${ }^{11}$ Furthermore, pre-lubrication makes HPCs easier to use because manual lubrication is not needed, which supports individuals with impaired dexterity. ${ }^{12}$

Given these benefits, one might assume that HPCs would be the prevailing catheter type. In 2008, Woodbury et al. reported that $74 \%$ of Canadian IC-users utilized non-HPCs, while only a minority used HPCs $(15 \%)$ or a combination of both $(11 \%) .{ }^{13}$ Since HPCs are more expensive than non-HPCs (both inside and outside of North America) ${ }^{14,15}$ and most Canadian provinces provide only limited support for intermittent catheters ${ }^{16}$, SCl-induced financial hardship makes it difficult to pay for HPCs out-of-pocket. ${ }^{17}$

With a recommended IC frequency of 4 to 6 times per day ${ }^{18}$ and the consequent total time requirement, time needed to perform IC remains a paramount aspect of the catheterization process. The significant IC time requirement can be taxing on personal relationships and may reduce available leisure time thereby resulting in inter- and intrapersonal strains. Further, it may be a disadvantage in the workforce due to out-of-home IC challenges, such as small toilets and hygiene issues. ${ }^{19}$ In addition, there may be a burden associated with self-catheterization that could be exacerbated by a perceived need to carry equipment such as wipes and hand sanitizer in order to perform IC outside the home setting. Other challenges of IC include opening the catheter packaging, preparing and inserting the catheter for catheterization, particularly for those with impaired dexterity. ${ }^{20,21}$

Considering the lack of evidence on whether HPCs or non-HPCs are more efficient with respect to time required for bladder management and the aforementioned characteristics and limitations, our aim was to compare both types of catheters regarding time needed to perform IC and user satisfaction. 
medRxiv preprint doi: https://doi.org/10.1101/2021.08.16.21253936; this version posted August 18, 2021. The copyright holder for this preprint (which was not certified by peer review) is the author/funder, who has granted medRxiv a license to display the preprint in perpetuity. All rights reserved. No reuse allowed without permission.

\section{MATERIALS AND METHODS}

\section{Ethics, study design and participants}

This pilot cross-over randomized controlled trial (RCT) was approved by the University of British Columbia (UBC) Research Ethics Board (H17-03228) and Vancouver Coastal Health (V17-03228), and registered at clinicaltrials.gov (NCT05003999), while conforming to the Declaration of Helsinki. Our target number of participants $(n=20)$ for this pilot cross-over RCT is in line with general recommendations from the literature. ${ }^{22,23,24}$ Sixtyfive individuals were screened between December 2018 and April 2019 according to the inclusion and exclusion criteria from which 21 individuals were invited for a baseline visit (Fig. 1 , the consort flow diagram $)^{25}$. The criteria were as follows: inclusion - female or male, age 18 years or older, presenting with chronic (>1-year post-injury) $\mathrm{SCl}$ at any spinal level, hand function sufficient to perform IC, fluent in English, not being pregnant, and without history of urinary diversion; exclusion - acute medical issues that would adversely affect participation in the study and members of the investigational team or their immediate family. After obtaining informed consent, 20 individuals were assigned a unique number during the baseline visit. Furthermore, neurological level and completeness of injury were classified in accordance with the International Standards for Neurological Classification of $\mathrm{SCl}$ $(\text { ISNCSCI })^{26}$ by a physician generating a grade on the American Spinal Injury Association impairment scale (AIS). Urine samples were collected to exclude or confirm UTIs (i.e., urine cultures and clinical symptoms) ${ }^{27}$ and in all female participants to confirm the absence of pregnancy. One eligible individual withdrew due to personal reasons, who was replaced by an eligible backup (i.e. screening individual \#21). After enrollment into the study, participants were randomized into two groups (i.e., starting with an HPC or non-HPC, allocation ratio 1:1) using a random sequence generator. Thereafter, participants underwent the first assessment followed by the second cross-over assessment within 10 days. Participants were followed up 5 to 10 days later via phone regarding potential adverse events (AEs). All catheters were provided by Coloplast A/S (Humlebæk, Denmark), i.e., HPC (SpeediCath $\circledast$ ) and non-HPC (Self-Cath®). For non-HPC, lubrication jelly $\left(\mathrm{MUKO}{ }^{\circledR}\right.$, $3.5 \mathrm{~g}$ package, Cardinal Health Canada Inc, Toronto, Canada) was provided.

\section{Primary and secondary outcome objectives}

The two primary outcome objectives of this study were the time needed to perform IC and user satisfaction (between HPC and non-HPC). The secondary outcome objectives were time needed to perform IC with respect to the participants' level of injury and catheter use in daily life.

\section{$\underline{\text { Assessment visits }}$}

All assessments were performed at UBC, Vancouver, Canada. A predetermined 13 step IC protocol was drafted together with individuals with $\mathrm{SCl}$ performing IC (Table 2). At each assessment visit, participants performed a guided test run to familiarize themselves with the protocol. Then, each step was recorded separately. To ensure discretion, one investigator was situated inside the bathroom behind a curtain. This investigator instructed the participant to "start" each step at which point the investigator outside started the timer. After completion of each step, the participant said "I'm done" and the timer was stopped. Subsequently, the participant moved on to perform the next step of the protocol. At the end of each assessment, participants completed a questionnaire (see supplementary Fig. 1 and 2) regarding their catheter satisfaction. At the end of the second visit, participants were also asked about their preference between the two catheters. 
medRxiv preprint doi: https://doi.org/10.1101/2021.08.16.21253936; this version posted August 18, 2021. The copyright holder for this preprint (which was not certified by peer review) is the author/funder, who has granted medRxiv a license to display the preprint in perpetuity.

All rights reserved. No reuse allowed without permission.

\section{Statistical analysis}

Statistical analyses were conducted using STATA 15 (StataCorp, College Station, TX, USA). Data are presented as raw values and percentages. Results are presented as median with interquartile range (IQR). In addition, range (i.e., min - max) is provided for age and time post injury. Non-parametric statistics were conducted, i.e., the Wilcoxon signed-rank test for primary and secondary outcomes (i.e., all variables except for the preferred catheter question which was tested with the Wilcoxon rank-sum test). All statistical tests were two-sided, and $p$ $<0.05$ was considered statistically significant. 


\section{RESULTS}

\section{Participant characteristics}

Twenty participants (five females) with a median age of 45 years (36 - 53, range 26 $65)$ and median time post injury of 14 years $(10-26$, range $3-46)$ completed the study (Table 1). The majority were daily non-HPCs $(75 \%, 15 / 20)$ users. One participant had a symptomatic UTI six days after the second assessment and was treated with antibiotics appropriately.

\section{Time comparison between HPC and non-HPC}

Table 2 highlights the time comparison between HPC and non-HPC for each of the 13 steps and in total. Total time taken to execute all 13 steps (i.e., from entering to exiting the bathroom) was 90 seconds shorter when using HPC compared to non-HPC [283 s (242 $352)$ vs. 373 (249 - 441), $p=0.01$ ]. Total time before the actual use of a catheter (i.e., steps 1 to 5 , table 2) was not statistically different between HPCs and non-HPCs [86 s (71 - 119) vs. 95 (74 - 121), $p=0.296]$. Similarly, there was no significant difference in total time taken post catheter use (i.e., steps 10 to 13, table 2) between HPCs and non-HPCs [88 s (69-110) vs. 88 (71 - 104), $p=0.218$ ]. However, the grouped steps involving catheter use (i.e., steps 6 to 9 , table 2), showed that the HPC group spent significantly less time than the non-HPC group [119 s (73 - 133) vs. 160 (85 - 222), $p=0.014$ ]. Of the individual steps, only the time taken to prepare the catheter was statistically significantly shorter for HPC compared to non-HPC $(p=0.002)$.

\section{Participants' satisfaction of HPC and non-HPC use}

HPC use was associated with significantly higher scores for "easiness to prepare" [5 (4 - 5) vs. 4 (2 - 4), p=0.047] and "did not feel burning" [5 (4 - 5) vs. 4 (3 - 5), p=0.042] compared to non-HPC. There were no statistical differences in any of the remaining scores (Table 3).

Time comparison with respect to the participants' level of injury and catheter use in daily life

For tetraplegic participants (9/20), total time taken to execute all 13 steps [300 s (249 - 352) vs. 421 (398 - 515), $p=0.139$ ], total time before using a catheter [89 s (78 - 107) vs. 99 (83 - 124), $p=0.214]$, and total time of catheter use [119 s (71 - 160) vs. 221 (163 - 241), $\mathrm{p}=0.214]$ were all shorter when using a HPC compared to a non-HPC but did not yield statistical significance (table 4). Total time post catheterization was similar between HPCs and non-HPCs [94 s (71 - 108) vs. 92 (84 - 97), $p=0.214$ ]. For paraplegic participants (11/20), total time overall was significantly shorter when using HPC compared to a non-HPC [272 s (210 - 353) vs. 296 (225 - 433), p=0.041]. There was no significant difference between HPCs and non-HPCs for total time before [86 s (66 - 130) vs. 86 (65 - 119), $p=0.657$ ], during [118 s $(80-124)$ vs. 128 (83 - 167), $p=0.062$ ] or post catheter use [78 s (69 - 105) vs. 71 (69-111), $\mathrm{p}=0.594]$.

For daily HPC users (5/20), total time overall [249 s (235 - 300) vs. 421 (241 - 491), $\mathrm{p}=0.08$ ], before [89 s $(75-131)$ vs. $119(83-124), p=0.345]$, during [75 s $(61-119)$ vs. 201 (102 - 221), $p=0.08$ ] and post catheter use [85 s (71 - 108) vs. 97 (87 - 111), $p=0.225]$ were all shorter with HPC compared to non-HPC, but without significant differences (Table 4).

For daily non-HPC users (15/20), total time overall was significantly shorter with HPC compared to non-HPC [285 s (253 - 353) vs. 348 (257 - 433), p=0.047]. Total time before [86 $s(68-107)$ vs. $92(71-104), p=0.364]$ and during catheter use [119 s (71 - 160) vs. 221 (163 - 241), $p=0.214]$ were shorter with HPC compared to non-HPC but without statistical 
medRxiv preprint doi: https://doi.org/10.1101/2021.08.16.21253936; this version posted August 18, 2021. The copyright holder for this preprint (which was not certified by peer review) is the author/funder, who has granted medRxiv a license to display the preprint in perpetuity.

All rights reserved. No reuse allowed without permission.

significance. Total time post catheter use [HPC 90 s (69 - 105) vs. non-HPC 84 (70 - 97), $\mathrm{p}=0.496)$ ] was similar for both. For participants with either tetra- and paraplegia as well as for HPC or non-HPC users, only step 'prepare catheter' was significantly shorter when using HPC compared to non-HPC (Table 4). 


\section{DISCUSSION}

To our knowledge, this is a novel cross-over RCT that quantifies the time taken to perform IC for individuals with SCI. A previous study examined preference and patient-reported time needed for catheterization across two coated catheters in a population of IC users ${ }^{28}$, but did not report quantitative measures of catheterization time, and examined two coated catheters in an overall IC population.

Twenty participants were timed while performing IC using HPCs and non-HPCs. Our results showed a substantial temporal burden from performing IC, independent of catheter type. The 90 second difference in median total time needed to perform IC between HPCs and non-HPC, corresponding to a $24 \%$ reduction in total time spent, was not only statistically significant but represents a meaningful difference. Considering an IC frequency of 4 to 6 times a day, those using HPCs will spend less than 24 minutes a day, while using non-HPCs will require around 31 minutes per day. This difference of 7 minutes per day adds up to 45 hours per year which roughly corresponds to one week of full-time employment. Arguably, this time difference may be important for all individuals, employers, and society. Even with HPCs being significantly faster to use, the temporal burden of IC remains significant regardless of catheter technology. As an illustrative example, an able-bodied person spends about 22 seconds $^{29}$ to void. If we assume one person would spend the average time for each relevant step presented in table 2 , this person would spend about 90 seconds per void or 7.5 minutes per day. In comparison, spending 24 to 31 minutes per day on IC clearly poses a significant temporal burden.

This substantial IC time use adds an additional item to the list of concerns faced by $\mathrm{SCl}$ individuals (including concerns such as difficulties finding accessible bathrooms, feeling of embarrassment and lack of privacy). ${ }^{30}$ In addition to posing an obstacle to maintaining efficient work hours ${ }^{31}$, the temporal burden may even exacerbate difficulties with adherence to IC as previously reported in the $\mathrm{SCl}$ population. ${ }^{32}$ Therefore, speed and efficiency of catheterization remains a high priority for individuals with $\mathrm{SCl}$.

The difference in total time use across catheters was mainly attributed to the steps involving direct catheter use, while remaining steps had less impact overall (table 2). For example, there was a $63 \%$ reduction in median total time taken to prepare HPCs compared to non-HPCs while the time taken to exit the bathroom was similar between the catheters. This pattern applied collectively to all subgroups (i.e., individuals with tetraplegia or paraplegia, daily users of HPCs or non-HPCs) which may be explained by the properties of each catheter. For example, there is no requirement to manually lubricate HPCs. In addition, preparation of non-HPCs require individuals to open lubricant packaging and maintain at least a clean, if not sterile, technique until the insertion of the catheter. These requirements do not apply to HPCs.

Dexterity is an important factor that determines the difficulty of performing IC. ${ }^{33}$ Studies are still divided as to whether HPCs are easier or more difficult to handle. ${ }^{34,35} \mathrm{We}$ hypothesized that individuals with tetraplegia would experience difficulties in handling HPCs due to impaired hand function compared to individuals with paraplegia. While both groups spent a similar time to prepare HPCs (16 vs 15 seconds), individuals with tetraplegia needed significantly more time (67 vs. 21 seconds, $p=0.003$ ) to prepare (i.e., unpack and lubricate) non-HPCs, than those with paraplegia.

Individuals rated HPCs to be easier to prepare than non-HPCs as well as causing less urethral burning sensation, which could be due to the need to lubricate non-HPCs prior to insertion. Even though there were no statistical differences (i.e., comparing the raw medians) in the remaining 11 satisfaction scores, HPCs scores were better in 6 , while the 
medRxiv preprint doi: https://doi.org/10.1101/2021.08.16.21253936; this version posted August 18, 2021. The copyright holder for this preprint (which was not certified by peer review) is the author/funder, who has granted medRxiv a license to display the preprint in perpetuity.

All rights reserved. No reuse allowed without permission.

remaining 5 were all tied. Several studies have reported participants finding HPCs easier to use compared to non-HPCs. ${ }^{36,37}$ To ensure that the results were not influenced by status quo bias, we split the sample analysis into subgroups depending on which type of catheter participants were regularly using (i.e., HPC vs non-HPC users). The results showed that no matter which type of catheter individuals were regularly using, participants catheterized faster with HPCs than with non-HPCs, driven by the preparation step.

While this study was intended to gain a first impression of the temporal burden associated with IC in individuals with $\mathrm{SCl}$, the key limitation of this study was the relatively small sample size. Nevertheless, this study provides evidence that individuals with $\mathrm{SCl}$ performing IC could benefit from using HPCs with regard to a better user satisfaction and a lesser temporal burden. However, other factors playing significant roles in the lives of individuals with $\mathrm{SCl}$ must be considered. Ultimately, the ability for this cohort to use HPC depend on a host of factors, including coverage provided by the respective health care system, re-use (cost amplification associated with single use catheters) ${ }^{38}$ and environmental burden (i.e., 5 HPCs versus re-using 1 or 2 non-HPCs per day). ${ }^{39}$

\section{CONCLUSION}

This pilot cross-over RCT provides evidence for a substantial IC time requirement for individuals with $\mathrm{SCI}$, independent of the catheter type, with potential negative implications on levels of intra- and interpersonal stress, overall burden of $\mathrm{SCl}$, workforce opportunities and IC compliance. The significance of reducing the time needed for IC while protecting the lower urinary tract makes it imperative that IC is performed efficiently which, in the context of this study, points to the merits of HPCs. 
medRxiv preprint doi: https://doi.org/10.1101/2021.08.16.21253936; this version posted August 18, 2021. The copyright holder for this preprint (which was not certified by peer review) is the author/funder, who has granted medRxiv a license to display the preprint in perpetuity.

All rights reserved. No reuse allowed without permission.

\section{ACKNOWLEDGMENTS}

Andrei V. Krassioukov and Matthias Walter had full access to all the data in the study and take responsibility for the integrity of the data and the accuracy of the data analysis.

Study concept and design:

Karthik Gopalakrishnan, Nick Fabrin Nielsen, Andrea Ramirez, Jeppe Sørensen, Andrei V.

Krassioukov, and Matthias Walter

Generation of the random allocation sequence, enrollment of participants, and assignment of participants to interventions:

Karthik Gopalakrishnan, Andrea Ramirez, and Matthias Walter

Acquisition of data:

Karthik Gopalakrishnan, Andrea Ramirez, Andrei V. Krassioukov, and Matthias Walter

Analysis and interpretation of data:

Karthik Gopalakrishnan, Nick Fabrin Nielsen, Andrea Ramirez, Jeppe Sørensen, Andrei V.

Krassioukov, and Matthias Walter

Drafting of the manuscript:

Karthik Gopalakrishnan and Nick Fabrin Nielsen

Critical revision of the manuscript for important intellectual content:

Andrea Ramirez, Jeppe Sørensen, Andrei V. Krassioukov, and Matthias Walter

Statistical analysis:

Karthik Gopalakrishnan and Matthias Walter

\section{Funding:}

This study was supported by an unrestricted research grant from Coloplast A/S, Humlebæk, Denmark (grant number COLO-AK-NLUTD-SCI: F18-03036). The funder had no role in data collection or on decision to publish. The funder was involved in the study design, interpretation of the data, and preparation as well as review of the manuscript.

Dr. Walter was supported by a 2017-2019 Michael Smith Foundation for Health Research (MSFHR) and Rick Hansen Foundation Postdoctoral Research Trainee Award (Grant number 17110). Dr. Krassioukov research is supported by the Endowed Chair in Rehabilitation Medicine, ICORD, The University of British Columbia.

Supervision:

Andrei V. Krassioukov and Matthias Walter

Other:

$\mathrm{N} / \mathrm{A}$. 


\section{REFERENCES}

1. Hicken BL, Putzke JD, Richards JS. Bladder management and quality of life after spinal cord injury. Am J Phys Med Rehabil 2001;80:916-22.

2. Yildiz N, Akkoc Y, Erhan B, Gunduz B, Yilmaz B, Alaca R, et al. Neurogenic bladder in patients with traumatic spinal cord injury: treatment and follow-up. Spinal Cord 2014;52:462-7.

3. Blok B, Castro-Diaz D, Del Popolo G, Groen J, Hamid R, Karsenty G, et al. European Association of Urology (EAU) Guidelines on Neuro-Urology. 2020 Edition. vol. presented, European Association of Urology Guidelines Office; 2020.

4. Weynants L, Hervé F, Decalf V, Kumps C, Pieters R, de Troyer B, et al. Clean Intermittent Self-Catheterization as a Treatment Modality for Urinary Retention: Perceptions of Urologists. Int Neurourol J 2017;21:189-96.

5. Campeau L, Shamout S, Baverstock RJ, Carlson K V, Elterman DS, Hickling DR, et al. Canadian Urological Association Best Practice Report: Catheter use. Can Urol Assoc J 2020;14:E281-9.

6. Waller L, Jonsson O, Norlen L, Sullivan L. Clean Intermittent Catheterization in Spinal Cord Injury Patients: Long-Term Followup of a Hydrophilic Low Friction Technique. J Urol 1995;153:345-8.

7. Pachler, Frimodt $\square$ Møller. A comparison of prelubricated hydrophilic and non $\square$ hydrophilic polyvinyl chloride catheters for urethral catheterization. BJU Int 1999;83:767-9.

8. Rognoni C, Tarricone R. Intermittent catheterisation with hydrophilic and nonhydrophilic urinary catheters: systematic literature review and meta-analyses 2017.

9. Christison K, Walter M, Wyndaele J-JJM, Kennelly M, Kessler TM, Noonan VK, et al. Intermittent Catheterization: The Devil Is in the Details. J Neurotrauma 2018;35:985-9.

10. van Zyl M, Seirlis A, Terry D, Visser A, Campbell R, Scriba E, et al. Best practice recommendations for bladder management in spinal cord afflicted patients in South Africa. South African Med J 2019;109.

11. Stensballe J, Looms D, Nielsen PN, Tvede M. Hydrophilic-Coated Catheters for Intermittent Catheterisation Reduce Urethral Micro Trauma: A Prospective, Randomised, Participant-Blinded, Crossover Study of Three Different Types of Catheters. Eur Urol 2005;48:978-83.

12. Klingler HC. A comparison of pre-lubricated hydrophilic and non-hydrophilic polyvinyl chloride catheters for urethral catheterization. Curr Opin Urol 1999;9:451.

13. Woodbury MG, Hayes KC, Askes HK. Intermittent catheterization practices following spinal cord injury: a national survey. Can J Urol 2008;15:4065. 
medRxiv preprint doi: https://doi.org/10.1101/2021.08.16.21253936; this version posted August 18, 2021. The copyright holder for this preprint (which was not certified by peer review) is the author/funder, who has granted medRxiv a license to display the preprint in perpetuity.

All rights reserved. No reuse allowed without permission.

14. Clark JF, Mealing SJ, Scott DA, Vogel LC, Krassioukov A, Spinelli M, et al. A costeffectiveness analysis of long-term intermittent catheterisation with hydrophilic and uncoated catheters. Spinal Cord 2016;54:73-7.

15. Watanabe T, Yamamoto S, Gotoh M, et al. Cost-Effectiveness Analysis of Long-Term Intermittent Self-Catheterization with Hydrophilic-Coated and Uncoated Catheters in Patients with Spinal Cord Injury in Japan. LUTS Low Urin Tract Symptoms. 2017;9(3):142-150.

16. Welk B, Isaranuwatchai W, Krassioukov A, Torp LH, Elterman D. Cost-effectiveness of hydrophilic-coated intermittent catheters compared with uncoated catheters in Canada: a public payer perspective. J Med Econ 2018;21:639-48.

17. Gupta S, McColl MA, Guilcher SJT, Smith K. Managing Medication Cost Burden: A Qualitative Study Exploring Experiences of People with Disabilities in Canada. Int J Environ Res Public Health 2019;16:3066.

18. Taweel W Al, Seyam R. Neurogenic bladder in spinal cord injury patients. Res Reports Urol 2015;7:85-99.

19. Goldstine J, Leece R, Samas S, Zonderland R. In Their Own Words: Adults' Lived Experiences With Intermittent Catheterization . J Wound, Ostomy, Cont Nurs 2019;46:513-8.

20. Taskinen S, Fagerholm R, Ruutu M. Patient experience with hydrophilic catheters used in clean intermittent catheterization. J Pediatr Urol 2008;4:367-71.

21. Logan K, Shaw C, Webber I, Samuel S, Broome L. Patients' experiences of learning clean intermittent self $\square$ catheterization: a qualitative study . J Adv Nurs 2008;62:32-40.

22. Hill R. What Sample Size is "Enough" in Internet Survey Research. Interpersonal Computing and Technology: An Electronic Journal for the 21st Century 1998; 6:3-4.

23. Johanson GA, Brooks GP. Initial Scale Development: Sample Size for Pilot Studies. Educ Psychol Meas. 2010;70(3):394-400.

24. Whitehead AL, Julious SA, Cooper CL, Campbell MJ. Estimating the sample size for a pilot randomised trial to minimise the overall trial sample size for the external pilot and main trial for a continuous outcome variable. Julious SA, ed. Stat methods Med Res. 2016;25(3):1057-1073.

25. Schulz KF, Altman DG, Moher D. CONSORT 2010 statement: updated guidelines for reporting parallel group randomised trials . PLoS Med . 2010;7(3):e1000251e1000251. doi:10.1371/journal.pmed.1000251

26. Kirshblum SC, Waring W, Biering-Sorensen F, Burns SP, Johansen M, Schmidt-Read $\mathrm{M}$, et al. Reference for the 2011 revision of the international standards for neurological classification of spinal cord injury. J Spinal Cord Med 2011;34:547-54. 
medRxiv preprint doi: https://doi.org/10.1101/2021.08.16.21253936; this version posted August 18, 2021. The copyright holder for this preprint (which was not certified by peer review) is the author/funder, who has granted medRxiv a license to display the preprint in perpetuity.

All rights reserved. No reuse allowed without permission.

27. Hooton TM, Bradley SF, Cardenas DD, et al. Diagnosis, Prevention, and Treatment of Catheter-Associated Urinary Tract Infection in Adults: 2009 International Clinical Practice Guidelines from the Infectious Diseases Society of America. Clin Infect Dis. 2010;50(5):625-663.

28. Pascoe G, Clovis S. Evaluation of two coated catheters in intermittent selfcatheterization. Br J Nurs 2001;10:325-9.

29. Lum M. The law of urination. Australas Sci 2014;35:42.

30. Cobussen-Boekhorst JGL, Hermeling E, Heesakkers JP, van Gaal B. Patients' experience with intermittent catheterisation in everyday life. J Clin Nurs 2016;25:125361.

31. Bakes B. The lived experience of self-intermittent catheterisation in people with spinal cord injury. JARNA Off J Australas Rehabil Nurses' Assoc 2014;17:20.

32. Lim S, Lee H, Davis M, Park K. Perceived barriers and difficulties of intermittent catheterization: In Korean patients with spinal dysraphism and their parents. Neurourol Urodyn 2016;35:395-9.

33. Seth JH, Haslam C, Panicker JN. Ensuring patient adherence to clean intermittent self-catheterization. Patient Prefer Adherence 2014;8:191.

34. Chick HE, Hunter KF, Moore KN. Parent and child experiences using a hydrophilic or reused PVC catheter for intermittent catheterisation. J Clin Nurs 2013;22:513-20.

35. Koeter I, Stensrod G, Nilsen AH, Lund R, Haslam C, Seze M De, et al. User perception of a new hydrophilic-coated male urinary catheter for intermittent use. Nurs Open 2019;6:116-25.

36. Ridder DJMK De, Everaert K, Fernández LG, Valero JVF, Durán AB, Abrisqueta MLJ, et al. Intermittent Catheterisation with Hydrophilic-Coated Catheters (SpeediCath) Reduces the Risk of Clinical Urinary Tract Infection in Spinal Cord Injured Patients: A Prospective Randomised Parallel Comparative Trial. Eur Urol 2005;48:991-5.

37. Domurath B, Kutzenberger J, Kurze I, Knoth HS. Clinical evaluation of a newly developed catheter (SpeediCath Compact Male) in men with spinal cord injury: residual urine and user evaluation. Spinal Cord 2011;49:817-21.

38. Saadat SH, Shepherd S, Van Asseldonk B, Elterman DS. Clean intermittent catheterization: Single use vs. reuse. Can Urol Assoc J 2019;13:64-9.

39. Avery M, Prieto J, Okamoto I, Cullen S, Clancy B, Moore KN, et al. Reuse of intermittent catheters: a qualitative study of IC users' perspectives. BMJ Open 2018;8:e021554. 


\section{TABLES}

Table 1 - Participant demographics and injury characteristics

\begin{tabular}{|c|c|c|c|c|c|c|c|}
\hline No. & NLI & AIS & Sex & $\begin{array}{c}\text { Age } \\
\text { range* }^{\text {[yrs] }}\end{array}$ & $\begin{array}{c}\text { TPI } \\
\text { range* }^{\text {[yrs] }}\end{array}$ & Catheter use in daily life & Catheter size $^{\$}[\mathrm{Fr}]$ \\
\hline 1 & C5 & $B$ & 1 & $36-40$ & $6-10$ & Non-HPC & 14 \\
\hline 2 & C5 & B & 2 & $26-30$ & $11-15$ & $\mathrm{HPC}$ & 14 \\
\hline 3 & C5 & B & 1 & $61-65$ & $11-15$ & HPC & 14 \\
\hline 4 & C5 & B & 1 & $36-40$ & $16-20$ & HPC & 14 \\
\hline 5 & C6 & A & 1 & $31-35$ & $11-15$ & Non-HPC & 16 \\
\hline 6 & C6 & A & 2 & $41-45$ & $21-25$ & Non-HPC & 14 \\
\hline 7 & C6 & B & 1 & $31-35$ & $1-5$ & Non-HPC & 14 \\
\hline 8 & C6 & B & 1 & $31-35$ & $6-10$ & $\mathrm{HPC}$ & 14 \\
\hline 9 & C6 & $B$ & 1 & 51-55 & $21-25$ & Non-HPC & 14 \\
\hline 10 & T2 & $A$ & 1 & $26-30$ & $11-15$ & Non-HPC & 14 \\
\hline 11 & T2 & $A$ & 1 & 51-55 & $36-40$ & Non-HPC & 14 \\
\hline 12 & T2 & B & 1 & 51-55 & $6-10$ & Non-HPC & 14 \\
\hline 13 & T3 & $A$ & 1 & $41-45$ & $26-30$ & Non-HPC & 16 \\
\hline 14 & T4 & A & 1 & $36-40$ & $16-20$ & Non-HPC & 14 \\
\hline 15 & T4 & A & 2 & $41-45$ & $26-30$ & Non-HPC & 12 \\
\hline 16 & $\mathrm{~T} 4$ & A & 2 & $51-55$ & $46-50$ & Non-HPC & 14 \\
\hline 17 & T5 & $A$ & 1 & $46-50$ & $1-5$ & HPC & 14 \\
\hline 18 & T12 & A & 2 & $51-55$ & $31-35$ & Non-HPC & 12 \\
\hline 19 & $\mathrm{~T} 12$ & $B$ & 1 & 61-65 & $11-15$ & Non-HPC & 12 \\
\hline 20 & L2 & $\mathrm{D}$ & 1 & 51-55 & $11-15$ & Non-HPC & 14 \\
\hline
\end{tabular}

* For information, such as age and time post injury, that would allow the study participant or their family, friends or neighbors to identify them, we chose to provide a 5-year range for age and time post injury, rather than revealing the actually numbers.

\$Size of catheter provided in the study was the same size as the participant's regular catheter.

AIS $=$ American Spinal Injury Association Impairment Scale, $\mathrm{C}=$ cervical, $\mathrm{Fr}=$ French, HPC = hydrophilic catheter, $\mathrm{L}=$ lumbar, $\mathrm{NLI}=$ neurological level of injury, No. = number, non-HPC $=$ non-hydrophilic catheter, $\mathrm{TPI}=$ time post-injury, $\mathrm{T}=$ thoracic yrs $=$ years. 
medRxiv preprint doi: https://doi.org/10.1101/2021.08.16.21253936; this version posted August 18, 2021. The copyright holder for this preprint (which was not certified by peer review) is the author/funder, who has granted medRxiv a license to display the preprint in perpetuity.

All rights reserved. No reuse allowed without permission.

Table 2 - Time comparison between HPC and non-HPC

\begin{tabular}{|c|c|c|c|c|}
\hline No. & Steps & HPC & non-HPC & p value \\
\hline 1 & Enter bathroom & $15(12-17)$ & $16(13-17)$ & 0.304 \\
\hline 2 & Wash hands & $28(23-35)$ & $34(22-38)$ & 0.097 \\
\hline 3 & Transfer to toilet & $9(8-15)$ & $10(7-12)$ & 0.455 \\
\hline 4 & Undress & $14(9-23)$ & $13(9-27)$ & 0.823 \\
\hline 5 & Clean genitalia & $29(20-43)$ & $30(22-48)$ & 0.657 \\
\hline \multicolumn{2}{|c|}{ Total time before catheter use } & $86(71-119)$ & $95(74-121)$ & 0.296 \\
\hline 6 & Prepare catheter & $15(10-20)$ & $41(20-69)$ & 0.002 \\
\hline 7 & Insertion & $28(15-41)$ & $44(15-66)$ & 0.279 \\
\hline 8 & Emptying & $36(17-65)$ & $43(25-53)$ & 0.737 \\
\hline 9 & Removal and disposal & $18(11-23)$ & $22(12-30)$ & 0.113 \\
\hline \multicolumn{2}{|c|}{ Total time during catheter use } & $119(73-133)$ & $160(85-222)$ & 0.014 \\
\hline 10 & Dress up & $32(14-41)$ & $31(15-42)$ & 0.305 \\
\hline 11 & Transfer to wheelchair & $5(4-7)$ & $9(8-11)$ & 0.18 \\
\hline 12 & Wash hands & $33(26-43)$ & $31(25-43)$ & 0.502 \\
\hline 13 & Exit bathroom & $20(17-24)$ & $20(16-23)$ & 0.794 \\
\hline \multicolumn{2}{|c|}{ Total time post catheter use } & $88(69-110)$ & $88(71-104)$ & 0.218 \\
\hline \multicolumn{2}{|c|}{ Total time needed to perform IC } & $283(242-352)$ & $373(249-441)$ & 0.010 \\
\hline
\end{tabular}

HPC = hydrophilic catheter, IC = Intermittent catheterization, No. = number of steps, non-HPC $=$ non-hydrophilic catheter. 
Table 3 - Comparison of participants' satisfaction between HPC and non-HPC

\begin{tabular}{|l|c|c|c|}
\hline Characteristics & HPC & non-HPC & p value \\
\hline Easy to prepare & $5(4-5)$ & $4(2-4)$ & 0.047 \\
\hline Easy to handle before insertion & $4(2-5)$ & $4(2-5)$ & 0.806 \\
\hline Easy to insert & $4(2-5)$ & $4(2-4)$ & 0.748 \\
\hline Able to drain bladder & $5(4-5)$ & $5(4-5)$ & 0.756 \\
\hline Easy to remove & $5(4-5)$ & $4(4-5)$ & 0.984 \\
\hline Easy to dispose & $5(4-5)$ & $4(4-5)$ & 0.553 \\
\hline Did not feel burning & $5(4-5)$ & $4(3-5)$ & 0.042 \\
\hline Did not feel pain & $4(4-5)$ & $4(3-5)$ & 0.173 \\
\hline I like to avoid adding lube & $5(4-5)$ & $4(3-5)$ & 0.564 \\
\hline Length of catheter sufficient & $5(4-5)$ & $5(4-5)$ & 0.657 \\
\hline Overall satisfaction & $4(3-5)$ & $3(2-5)$ & 0.344 \\
\hline Would recommend & $4(3-5)$ & $3(1-5)$ & 0.206 \\
\hline Prefer this catheter (only asked at last assessment) & $3(2-5)$ & $2(1-5)$ & 0.232 \\
\hline
\end{tabular}

$\mathrm{HPC}=$ hydrophilic catheter, non-HPC = non-hydrophilic catheter 
Table 4 - Time comparison between HPC and non-HPC with respect to the participants' neurological level of injury and type of catheter used in daily life.

\begin{tabular}{|c|c|c|c|c|c|c|c|c|c|c|c|c|c|}
\hline \multirow{2}{*}{ No. } & \multirow{2}{*}{ Steps } & \multicolumn{3}{|c|}{ Tetraplegia $(n=9)$} & \multicolumn{3}{|c|}{ Paraplegia $(n=11)$} & \multicolumn{3}{|c|}{ HPC-user $(n=5)$} & \multicolumn{3}{|c|}{ non-HPC user $(n=15)$} \\
\hline & & HPC & non-HPC & $p$ & HPC & non-HPC & $p$ & HPC & non-HPC & $p$ & HPC & non-HPC & $p$ \\
\hline 1 & Enter bathroom & $16(16-20)$ & $16(16-19)$ & 0.314 & $12(11-15)$ & $13(12-16)$ & 0.504 & $16(16-21)$ & $18(16-18)$ & 0.5 & $14(11-16)$ & $15(12-16)$ & 0.094 \\
\hline 2 & Wash hands & $27(23-33)$ & $34(31-37)$ & 0.066 & $29(24-35)$ & $29(21-39)$ & 0.79 & $26(22-27)$ & $34(31-35)$ & 0.08 & $30(24-36)$ & $34(21-40)$ & 0.443 \\
\hline 3 & Transfer to toilet $\dagger$ & $10(8-25)$ & $11(9-13)$ & 0.767 & $9(8-10)$ & $9(6-12)$ & 0.286 & $8(7-9)$ & $9(6-11)$ & 0.5 & $9(8-25)$ & $11(7-15)$ & 0.28 \\
\hline 4 & Undress & $18(12-41)$ & $17(12-31)$ & 0.678 & $11(9-18)$ & $10(9-25)$ & 0.477 & $18(12-34)$ & $16(12-25)$ & 0.345 & $12(9-20)$ & $11(9-27)$ & 0.733 \\
\hline 5 & Clean genitalia & $30(25-34)$ & $28(24-39)$ & 1.0 & $26(19-47)$ & $34(19-48)$ & 0.866 & $34(25-42)$ & $32(28-41)$ & 1.0 & $26(19-43)$ & $28(19-48)$ & 0.612 \\
\hline \multicolumn{2}{|c|}{ Total time before catheter } & $89(78-107)$ & $99(83-124)$ & 0.214 & $86(66-130)$ & $86(65-119)$ & 0.657 & $89(75-131)$ & $119(83-124)$ & 0.345 & $86(68-107)$ & $92(71-104)$ & 0.364 \\
\hline 6 & Prepare catheter & $16(11-20)$ & $67(46-81)$ & 0.038 & $15(9-24)$ & $21(14-45)$ & 0.023 & $15(11-17)$ & $46(38-67)$ & 0.043 & $16(10-24)$ & $36(16-78)$ & 0.021 \\
\hline 7 & Insertion & $32(19-79)$ & $63(55-124)$ & 0.441 & $26(14-33)$ & $31(13-51)$ & 0.534 & $19(11-26)$ & $51(22-63)$ & 0.225 & $30(17-48)$ & $38(13-70)$ & 0.57 \\
\hline 8 & Emptying & $25(16-32)$ & $27(17-48)$ & 0.767 & $42(30-67)$ & $45(37-57)$ & 0.477 & $27(25-32)$ & $22(17-48)$ & 0.686 & $40(16-67)$ & $45(36-56)$ & 1.0 \\
\hline 9 & $\begin{array}{l}\text { Removal and } \\
\text { disposal }\end{array}$ & $19(15-32)$ & $25(18-43)$ & 0.286 & $15(8-22)$ & $16(10-30)$ & 0.248 & $15(13-19)$ & $25(18-30)$ & 0.08 & $18(8-32)$ & $18(11-30)$ & 0.379 \\
\hline \multicolumn{2}{|c|}{ Total time during catheter } & $119(71-160)$ & $221(163-241)$ & 0.139 & $\begin{array}{c}118(80- \\
124)\end{array}$ & $\begin{array}{c}128(83- \\
167)\end{array}$ & 0.062 & $75(61-119)$ & $201(102-221)$ & 0.08 & $120(80-158)$ & $158(84-223)$ & 0.061 \\
\hline 10 & Dress up & $32(21-36)$ & $39(15-42)$ & 0.678 & $32(12-43)$ & $30(15-42)$ & 0.197 & $36(23-36)$ & $41(39-43)$ & 0.225 & $32(12-43)$ & $28(11-42)$ & 0.755 \\
\hline 11 & $\begin{array}{l}\text { Transfer to } \\
\text { wheelchair *** }\end{array}$ & $N / A^{*}$ & $N / A^{*}$ & $N / A^{*}$ & $5(4-7)$ & $9(8-11)$ & 0.18 & $N / A^{* *}$ & $N / A^{* *}$ & $N / A^{* *}$ & $5(4-7)$ & $9(8-11)$ & 0.18 \\
\hline 12 & Wash hands & $32(26-39)$ & $32(28-42)$ & 0.086 & $33(23-49)$ & $27(24-44)$ & 0.929 & $26(25-32)$ & $28(25-32)$ & 0.686 & $35(30-49)$ & $40(25-47)$ & 0.57 \\
\hline 13 & Exit bathroom & $24(18-26)$ & $21(20-25)$ & 0.766 & $20(14-20)$ & $18(15-21)$ & 0.859 & $18(17-26)$ & $21(18-25)$ & 0.686 & $20(14-24)$ & $20(15-23)$ & 0.887 \\
\hline \multicolumn{2}{|c|}{ Total time after catheter } & $94(71-108)$ & $92(84-97)$ & 0.214 & $78(69-105)$ & $71(69-111)$ & 0.594 & $85(71-108)$ & $97(87-111)$ & 0.225 & $90(69-105)$ & $84(70-97)$ & 0.496 \\
\hline \multicolumn{2}{|c|}{$\begin{array}{l}\text { Total time needed to } \\
\text { perform IC }\end{array}$} & $300(249-352)$ & $421(398-515)$ & 0.139 & $\begin{array}{l}272(210- \\
353)\end{array}$ & $\begin{array}{c}296(225- \\
443)\end{array}$ & 0.041 & $\begin{array}{l}249(235- \\
300)\end{array}$ & $421(241-491)$ & 0.08 & $285(253-353)$ & $348(257-433)$ & 0.047 \\
\hline
\end{tabular}

$t /^{\star}$ Participants with tetraplegia did only transfer from the sink to the toilet (i.e. step 3 ) by wheeling but did not transfer from the wheelchair onto the toilet. They performed catheterization while sitting in their wheelchair. ${ }^{*}$ HPC-user were all participants with tetraplegia. HPC $=$ hydrophilic catheter, IC = Intermittent catheterization, $n=$ number of participants, N/A = not applicable, No. = number of steps, non-HPC = non-hydrophilic 
medRxiv preprint doi: https://doi.org/10.1101/2021.08.16.21253936; this version posted August 18, 2021. The copyright holder for this preprint (which was not certified by peer review) is the author/funder, who has granted medRxiv a license to display the preprint in perpetuity.

All rights reserved. No reuse allowed without permission.

\section{FIGURE LEGEND}

Figure 1 - The Consort 2010 Flow Diagram.

$\mathrm{HPC}=$ hydrophilic catheter, non-HPC = non-hydrophilic catheter 


\section{Excluded $(n=1)$}

After randomiation, one participant withdrew due to personal reasons and was replaced by one eligible individual, who was initally assigned as a back up
Assessed for eligibility $(n=65)$

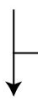

Eligible $(n=21)$



Enrolled $(n=20)$
Excluded $(n=44)$

Did not meet inclusion criteria $(n=43)$

Declined to participate $(n=1)$

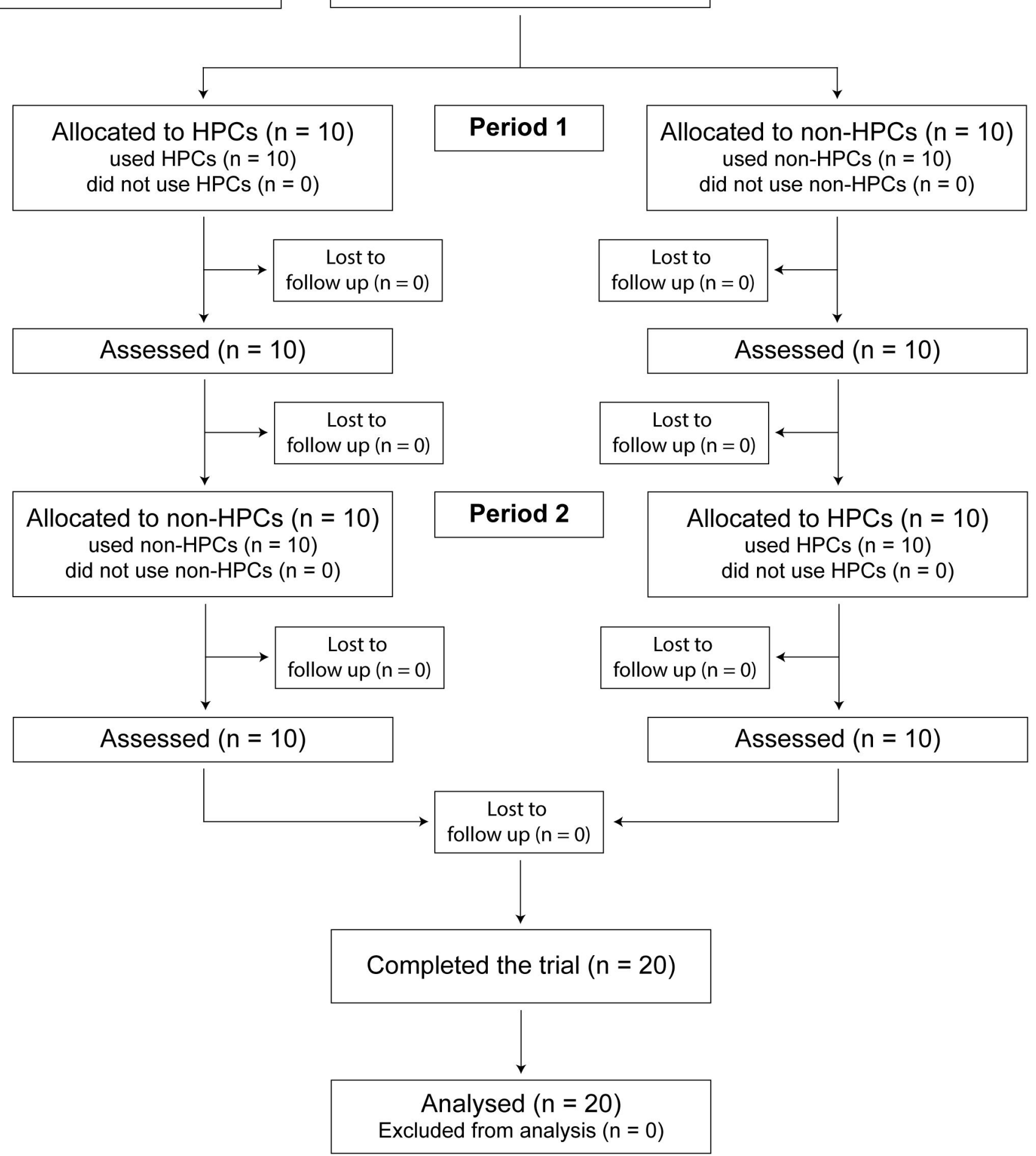

